\title{
Development and validation of a model to estimate the risk of acute ischemic stroke in geriatric patients with primary hypertension
}

\author{
Xifeng Zheng ${ }^{1 * \dagger}$, Fang Fang $^{2+}$, Weidong Nong ${ }^{3}$, Dehui Feng ${ }^{1}$ and Yu Yang ${ }^{1}$
}

\begin{abstract}
Objectives: This study aimed to construct and validate a prediction model of acute ischemic stroke in geriatric patients with primary hypertension.

Methods: This retrospective file review collected information on 1367 geriatric patients diagnosed with primary hypertension and with and without acute ischemic stroke between October 2018 and May 2020. The study cohort was randomly divided into a training set and a testing set at a ratio of 70 to $30 \%$. A total of 15 clinical indicators were assessed using the chi-square test and then multivariable logistic regression analysis to develop the prediction model. We employed the area under the curve (AUC) and calibration curves to assess the performance of the model and a nomogram for visualization. Internal verification by bootstrap resampling (1000 times) and external verification with the independent testing set determined the accuracy of the model. Finally, this model was compared with four machine learning algorithms to identify the most effective method for predicting the risk of stroke.

Results: The prediction model identified six variables (smoking, alcohol abuse, blood pressure management, stroke history, diabetes, and carotid artery stenosis). The AUC was 0.736 in the training set and 0.730 and 0.725 after resampling and in the external verification, respectively. The calibration curve illustrated a close overlap between the predicted and actual diagnosis of stroke in both the training set and testing validation. The multivariable logistic regression analysis and support vector machine with radial basis function kernel were the best models with an AUC of 0.710 .
\end{abstract}

Conclusion: The prediction model using multiple logistic regression analysis has considerable accuracy and can be visualized in a nomogram, which is convenient for its clinical application.

Keywords: Acute ischemic stroke, Geriatric patients, Machine learning, Multivariable logistic regression, Primary hypertension

\footnotetext{
* Correspondence: zhengxf@gdmu.edu.cn

${ }^{+}$Xifeng Zheng and Fang Fang are co-first authors.

1 Department of Geriatrics, Affiliated Hospital of Guangdong Medical

University, No.57, South of Renming Road, Zhanjiang, Guangdong 524001,

People's Republic of China

Full list of author information is available at the end of the article
}

(c) The Author(s). 2021 Open Access This article is licensed under a Creative Commons Attribution 4.0 International License, which permits use, sharing, adaptation, distribution and reproduction in any medium or format, as long as you give appropriate credit to the original author(s) and the source, provide a link to the Creative Commons licence, and indicate if changes were made. The images or other third party material in this article are included in the article's Creative Commons licence, unless indicated otherwise in a credit line to the material. If material is not included in the article's Creative Commons licence and your intended use is not permitted by statutory regulation or exceeds the permitted use, you will need to obtain permission directly from the copyright holder. To view a copy of this licence, visit http://creativecommons.org/licenses/by/4.0/ The Creative Commons Public Domain Dedication waiver (http://creativecommons.org/publicdomain/zero/1.0/) applies to the data made available in this article, unless otherwise stated in a credit line to the data. 


\section{Introduction}

According to estimates by the World Health Organization, stroke is the second leading cause of death that will account for 7.8 million deaths and 23 million first-time ischemic stroke events by 2030 [1]. Many risk factors for stroke, such as hypertension, dyslipidemia, diabetes, smoking, and alcohol consumption, have been identified [2]. With rising levels of prosperity and an aging population, the prevalence of hypertension in China has increased from $23.4 \%$ in 1991 to $28.6 \%$ in 2011 (concerning approximately 300 million adults), which places a huge burden on public health resources [3]. Hypertensive patients commonly suffer acute ischemic strokes, especially among the elderly with multiple risk factors.

Considering the high fatality and disability rates resulting from stroke, we intended to develop a practical prediction model by integrating the common risk factors observed in the clinic. It is beneficial to estimate the risk of acute ischemic stroke in geriatric patients with primary hypertension so that appropriate preventive measures can be taken. Nomograms have been widely used for medical diagnosis and prognosis evaluation in recent years $[4,5]$ for their user-friendliness. Our aim was to provide an individualized clinical decision tool for physicians.

\section{Materials and methods}

\section{Study design and data source}

This retrospective file review entailed the extraction of information on geriatric patients who were older than 60 years [6] and diagnosed with primary hypertension, whether or not they suffered an acute ischemic stroke, from the electronic medical record database of the affiliated hospital of Guangdong medical university from October 2018 to May 2020. Patients with detailed clinical information, biochemical, and imaging examinations were included in the study. The diagnosis of acute ischemic stroke was based on neuroimaging.

This resulted in the files of a total of 1367 patients being analyzed in this retrospective study and randomly divided these into a training set and a testing set in a ratio of 70 to $30 \%$.

\section{Study variables}

A total of 15 risk factors associated with stroke were included in the study based on the literature [1, 7-9] and are listed in Table 1 . Risk factors are indicators that can be easily assessed in clinical practice. All the risk factors were transformed into categorical variables to develop a nomogram. With this model, the sample size should be at least ten times greater than the number of variables [11].

Table 1 The risk factors with a definition in this study

\begin{tabular}{|c|c|}
\hline Risk factors & Definition \\
\hline Age (years) & $\begin{array}{l}\text { Between } 60 \text { and } 70 y, 70 \text { and } 80 y \text {, and } \geq 80 \text { y (the class interval included the lower value but excluded the higher } \\
\text { one) }\end{array}$ \\
\hline Sex & Female/Male \\
\hline Degree of hypertension & $\begin{array}{l}\text { Stage one }(\mathrm{SBP}=140-160 \mathrm{mmHg} \text { and/or } \mathrm{DBP}=90-100 \mathrm{mmHg}) \\
\text { Stage two }(\mathrm{SBP}=160-180 \mathrm{mmHg} \text { and/or } \mathrm{DBP}=100-110 \mathrm{mmHg}) \\
\text { Stage three }(\mathrm{SBP}>=180 \mathrm{mmHg} \text { and/or } \mathrm{DBP}>=110 \mathrm{mmHg})\end{array}$ \\
\hline Smoke & Yes/No (Based on the electronic medical record) \\
\hline Alcohol abuse & Yes/No (Based on the electronic medical record) \\
\hline $\begin{array}{l}\text { Blood pressure } \\
\text { management }\end{array}$ & Yes/No(Adhere to medication treatment and SBP < 140 mmHg [10]) \\
\hline Stroke history & Yes/No (Based on the electronic medical record) \\
\hline Diabetes history & Yes/No (Based on the electronic medical record) \\
\hline Coronary heart disease & Yes (Including paroxysmal or permanent atrial fibrillation)/No \\
\hline Total cholesterol & $\begin{array}{l}\text { Normal }(3.1-5.7 \mathrm{mmol} / \mathrm{L}) \\
\text { Up-regulation }(>5.7 \mathrm{mmol} / \mathrm{L})\end{array}$ \\
\hline Triglyceride & $\begin{array}{l}\text { Normal }(0.4-2.0 \mathrm{mmol} / \mathrm{L}) \\
\text { Up-regulation }(>2.0 \mathrm{mmol} / \mathrm{L})\end{array}$ \\
\hline LDL- cholesterol & $\begin{array}{l}\text { Normal }(1.8-3.36 \mathrm{mmol} / \mathrm{L}) \\
\text { Up-regulation }(>3.36 \mathrm{mmol} / \mathrm{L})\end{array}$ \\
\hline HDL- cholesterol & $\begin{array}{l}\text { Normal }(1.16-1.55 \mathrm{mmol} / \mathrm{L}) \\
\text { Up-regulation }(>1.55 \mathrm{mmol} / \mathrm{L})\end{array}$ \\
\hline Homocysteine & $\begin{array}{l}\text { Normal }(6.5-16.9 \mu \mathrm{mol} / \mathrm{L}) \\
\text { Up-regulation }(>16.9 \mu \mathrm{mol} / \mathrm{L})\end{array}$ \\
\hline Carotid artery stenosis & Yes/No (Based on the result of ultrasound) \\
\hline
\end{tabular}


Table 2 Baseline characteristics of the total cohort

\begin{tabular}{|c|c|c|c|c|}
\hline \multirow[t]{2}{*}{ Risk Factors } & \multicolumn{4}{|l|}{$n(\%)$} \\
\hline & Total $=1367$ & Stroke $=437$ & non-Stroke $=930$ & $P$-value \\
\hline 1.Age(years) & & & & 0.170 \\
\hline $60 y-70 y$ & $477(34.90)$ & 139(31.81) & 338(36.34) & \\
\hline $70 y-80 y$ & $573(41.91)$ & 198(45.31) & $375(40.32)$ & \\
\hline$>=80 y$ & $317(23.19)$ & $100(22.88)$ & $217(23.34)$ & \\
\hline 2.Gender & & & & $0.021^{*}$ \\
\hline Female & $592(43.30)$ & $169(38.67)$ & $423(45.48)$ & \\
\hline Male & $775(56.70)$ & 268(61.33) & $507(56.52)$ & \\
\hline 3.Degree of hypertension & & & & 0.071 \\
\hline Stage two & $447(32.70)$ & 158(36.16) & 289(31.08) & \\
\hline Stage three & $920(67.30)$ & $279(63.84)$ & $641(68.92)$ & \\
\hline 4. Smoke & & & & $<0.001^{*}$ \\
\hline Yes & 105(7.68) & $57(13.04)$ & $48(5.16)$ & \\
\hline No & $1262(92.32)$ & $380(86.96)$ & $882(94.84)$ & \\
\hline 5. Alcohol abuse & & & & $<0.001^{*}$ \\
\hline Yes & $98(7.17)$ & $54(12.36)$ & $44(4.73)$ & \\
\hline No & 1269(92.83) & 383(87.64) & $886(95.27)$ & \\
\hline 6.Blood pressure management & & & & $<0.001^{*}$ \\
\hline Yes & $688(50.33)$ & 128(29.30) & $560(60.22)$ & \\
\hline No & $679(49.67)$ & $309(70.70)$ & 370(39.78) & \\
\hline 7. Stroke history & & & & $<0.001^{*}$ \\
\hline Yes & $280(20.48)$ & 128(29.29) & 152(16.34) & \\
\hline No & 1087(79.52) & $309(70.71)$ & $778(83.66)$ & \\
\hline 8. Diabetes history & & & & $<0.001^{*}$ \\
\hline Yes & $377(27.57)$ & 147(33.64) & $230(24.73)$ & \\
\hline No & $990(72.43)$ & $290(66.36)$ & $700(75.27)$ & \\
\hline 9. Coronary heart disease & & & & 0.775 \\
\hline Yes & $302(22.10)$ & $94(21.51)$ & $208(22.37)$ & \\
\hline No & 1065(77.90) & $343(78.49)$ & $722(77.63)$ & \\
\hline 10. Total Cholesterol & & & & $<0.001^{*}$ \\
\hline Normal & 1125(82.30) & $336(76.89)$ & $789(84.84)$ & \\
\hline UP-regulation & $242(17.70)$ & $101(23.11)$ & 141(15.16) & \\
\hline 11. Triglyceride & & & & 0.180 \\
\hline Normal & $1151(83.54)$ & $356(81.46)$ & $786(84.52)$ & \\
\hline UP-regulation & $225(16.46)$ & $81(18.54)$ & 144(15.48) & \\
\hline 12. LDL-C & & & & $<0.001^{*}$ \\
\hline Normal & $997(72.93)$ & $289(66.13)$ & 708(76.13) & \\
\hline UP-regulation & $370(27.07)$ & 148(33.87) & $222(23.87)$ & \\
\hline 13. HDL-C & & & & 0.251 \\
\hline Normal & 1175(85.96) & $383(87.64)$ & 792(85.16) & \\
\hline UP-regulation & 192(14.04) & $54(12.36)$ & 138(14.84) & \\
\hline 14. Homocysteine & & & & 0.202 \\
\hline Normal & $671(49.08)$ & $226(51.72)$ & $445(47.85)$ & \\
\hline UP-regulation & $696(50.92)$ & $211(48.28)$ & $485(52.15)$ & \\
\hline
\end{tabular}


Table 2 Baseline characteristics of the total cohort (Continued)

\begin{tabular}{|c|c|c|c|c|}
\hline \multirow[t]{2}{*}{ Risk Factors } & \multicolumn{4}{|l|}{$\mathrm{n}(\%)$} \\
\hline & Total = 1367 & Stroke $=437$ & non-Stroke $=930$ & $P$-value \\
\hline 15. Carotid artery stenosis & & & & $0.004^{*}$ \\
\hline Yes & $78(5.71)$ & $37(8.47)$ & $41(4.41)$ & \\
\hline No & 1289(94.29) & $400(91.53)$ & 889(95.59) & \\
\hline
\end{tabular}

\section{Statistical analysis}

All variables were expressed as counts (\%). Statistical analysis was performed using $\mathrm{R}$ software 3.6.1(http:// www.R-project.org/). The risk factors showing a $P$-value $<0.05$ in the Chi-square test were regarded as statistically significant. Multivariable logistic regression analysis was used to identify the optimal variables for the construction of the prediction model. These variables were expressed as odds ratios (ORs) with 95\% confidence intervals (CIs) and P-values. The area under the curve (AUC) and calibration curves were used to assess the performance of the prediction model. A nomogram was developed to visualize the prediction model in a userfriendly manner $[12,13]$.

Furthermore, we applied four machine-learning classifiers (random forest, support vector machine with polynomial kernel, support vector machine with radial basis function kernel, and backpropagation neural network) using JupyterLab 1.2.6 (https://jupyterlab.readthedocs.io/ en) to compare the results with the multivariable logistic regression model. The best combination of parameters of the machine learning algorithms was identified based on the highest log-likelihood. The average log-likelihood over five repetitions of fivefold cross-validation was used to select the optimal parameters [14].

\section{Results}

\section{Baseline characteristics and optimal risk factors} identification

Among the 1367 patients diagnosed with primary hypertension between October 2018 and May 2020 in this study, 437 had suffered an acute ischemic stroke. A total of 959 patients were assigned to the training set and 408 to the testing set. Detailed information about the characteristics of patients in the total cohort and the training set are shown in Tables 2 and Table 3, respectively.

There were nine variables (gender, smoking, alcohol abuse, blood pressure management, a history of stroke, diabetes, carotid artery stenosis (CAS), total cholesterol, and LDL-cholesterol) with statistically significant differences $(P<0.05)$ in the chi-square test. Six variables (smoking, alcohol abuse, blood pressure management, stroke history, diabetes, CAS) showed a statistically significant difference $(P<0.05)$ in the multivariable logistic regression analysis. The results of the multivariable logistic regression analysis are displayed as forest plots in Fig. 1.

\section{Construction and assessment of the prediction nomogram}

The prediction model was constructed by multivariable logistic regression based on the six identified variables (smoking, alcohol abuse, blood pressure management, stroke history, diabetes, CAS). The nomogram in Fig. 2 visualizes the model in a user-friendly manner.

Nomogram interpretation: The observed value of each feature variable was assigned a certain number of points by drawing a vertical line towards the top points scale. The sum of the points for each variable corresponded to the individual risk of acute ischemic stroke. If we assume that a geriatric patient has a history of ischemic stroke, smoking and poor blood pressure management, but no alcohol abuse or carotid stenosis, we can calculate the score of each feature of the patient according to the value of each variable: smoking (68 points) + history of ischemic stroke (54 points) + poor blood pressure management (100 points) + without alcohol abuse or carotid stenosis $(0$ points $)=222$ total points. From the total points scale, a line perpendicular to the acute ischemic risk scale at the bottom shows that the probability of acute ischemic stroke occurrence is about $75 \%$.

The AUC of the prediction model was 0.736 in the training set, while the AUC after 1000-times bootstrap resampling was 0.730 and 0.725 in the external verification using the testing set (Fig. 3). The calibration curve illustrated an overlap between the probabilities of the predicted and actual diagnosis of stroke in both the training set and the testing set (Fig. 4).

\section{Multivariable logistic regression analysis and machine learning}

We constructed the prediction model based on the same variables using the five different algorithms, and verified them using the testing set. The multivariable logistic regression analysis and support vector machine with radial basis function kernel both achieved an AUC score of 0.71 that was better than the other three prediction models (Fig. 5).

\section{Discussion}

This study developed a practical nomogram that includes six variables that can be easily identified in the clinic to assist physicians in discriminating patients with 
Table 3 Baseline characteristics of the training set

\begin{tabular}{|c|c|c|c|c|}
\hline \multirow[t]{2}{*}{ Risk Factors } & \multicolumn{4}{|l|}{$n(\%)$} \\
\hline & Total $=959$ & Stroke $=309$ & non-Stroke $=650$ & $P$-value \\
\hline 1.Age(years) & & & & 0.389 \\
\hline $60 y-70 y$ & $325(33.89)$ & $96(31.07)$ & $229(35.23)$ & \\
\hline $70 y-80 y$ & $405(42.23)$ & 139(44.98) & $266(40.92)$ & \\
\hline$>=80 y$ & $229(23.88)$ & $74(23.95)$ & $155(23.85)$ & \\
\hline 2.Gender & & & & $0.027^{*}$ \\
\hline Female & 395(41.19) & $111(35.92)$ & 284(43.70) & \\
\hline Male & $564(58.81)$ & 198(64.08) & $366(56.30)$ & \\
\hline 3.Degree of hypertension & & & & 0.170 \\
\hline Stage two & $314(32.74)$ & $111(35.92)$ & 203(31.23) & \\
\hline Stage three & $645(67.26)$ & 198(64.08) & $447(68.77)$ & \\
\hline 4. Smoke & & & & $<0.001^{*}$ \\
\hline Yes & $77(8.03)$ & $44(14.24)$ & $33(5.08)$ & \\
\hline No & 882(91.97) & $265(85.76)$ & $617(94.92)$ & \\
\hline 5. Alcohol abuse & & & & $<0.001^{*}$ \\
\hline Yes & 69(7.19) & $40(12.95)$ & $29(4.46)$ & \\
\hline No & $890(92.81)$ & 269(87.05) & $621(95.54)$ & \\
\hline 6.Blood pressure management & & & & $<0.001^{*}$ \\
\hline Yes & 488(50.89) & 223(72.17) & $265(40.77)$ & \\
\hline No & $471(49.11)$ & $86(27.83)$ & $385(59.23)$ & \\
\hline 7. Stroke history & & & & $<0.001^{*}$ \\
\hline Yes & $206(21.48)$ & $91(29.45)$ & 115(17.69) & \\
\hline No & $753(78.52)$ & $218(70.55)$ & $535(82.31)$ & \\
\hline 8. Diabetes history & & & & $<0.001^{*}$ \\
\hline Yes & $264(27.53)$ & 101(32.69) & $163(25.08)$ & \\
\hline No & $695(72.47)$ & $208(67.31)$ & $487(74.92)$ & \\
\hline 9. Coronary heart disease & & & & 0.454 \\
\hline Yes & $211(22.00)$ & $63(20.39)$ & $148(22.77)$ & \\
\hline No & $748(78.00)$ & $246(79.61)$ & $502(77.23)$ & \\
\hline 10. Total Cholesterol & & & & $0.005^{*}$ \\
\hline Normal & 794(82.79) & $240(77.67)$ & $554(85.23)$ & \\
\hline UP-regulation & $165(17.21)$ & $69(22.33)$ & $96(14.77)$ & \\
\hline 11. Triglyceride & & & & 0.159 \\
\hline Normal & 798(83.21) & $249(80.58)$ & $549(84.46)$ & \\
\hline UP-regulation & 161(16.79) & $60(19.42)$ & $101(15.54)$ & \\
\hline 12. LDL-C & & & & $0.003^{*}$ \\
\hline Normal & $717(74.77)$ & $212(68.61)$ & $505(77.69)$ & \\
\hline UP-regulation & $242(25.23)$ & 97(31.39) & $145(22.31)$ & \\
\hline 13. HDL-C & & & & 0.765 \\
\hline Normal & $835(87.07)$ & $271(87.70)$ & $564(86.77)$ & \\
\hline UP-regulation & 124(12.93) & $38(12.30)$ & $86(13.23)$ & \\
\hline 14. Homocysteine & & & & 0.224 \\
\hline Normal & $477(49.74)$ & 163(52.75) & $314(48.31)$ & \\
\hline UP-regulation & $482(50.26)$ & $146(47.25)$ & $336(51.69)$ & \\
\hline
\end{tabular}


Table 3 Baseline characteristics of the training set (Continued)

\begin{tabular}{llll}
\hline Risk Factors & $\mathbf{n}(\mathbf{\%})$ & & \\
& Total $=\mathbf{9 5 9}$ & Stroke $=\mathbf{3 0 9}$ & non-Stroke $=\mathbf{6 5 0}$ \\
\hline $\begin{array}{ll}\text { 15. Carotid artery stenosis } \\
\text { Yes }\end{array}$ & & \\
No & $58(6.05)$ & $29(9.39)$ & 29(4.46) \\
\hline
\end{tabular}

high risk of stroke, enabling them to implement preventive measures as early as possible.

Blood pressure management is the most important variable that has a positive effect on stroke. With aging, the vascular elasticity decreases as a consequence of atherosclerosis. Thus, it is recommended that the systolic blood pressure in the elderly is less than $150 \mathrm{mmHg}$ [15]. A meta-analysis reported that there was a $41 \%$ reduction in stroke for every blood pressure reduction of $10 \mathrm{mmHg}$ systolic or $5 \mathrm{mmHg}$ diastolic [16]. Although various hypertension guidelines indicate a certain goal of blood pressure control, few large-scale clinical evidencebased data focus on hypertension or stroke in very elderly patients. Professional doctors should be aware of this practical clinical problem and pay attention to the notion of individualized blood pressure management in elderly patients [17], without ignoring the symptoms and feelings of very elderly patients. In addition to the absolute value of blood pressure, blood pressure variability deserves attention. Excessive blood pressure fluctuation in the morning is a classic phenomenon. Kario used ambulatory blood pressure monitoring and magnetic resonance imaging and demonstrated that an exaggerated early morning blood pressure surge was independently associated with stroke in elderly hypertensive patients. The risk of stroke in patients with a morning blood pressure surge $>55 \mathrm{mmHg}$ was 2.7 times higher than that in patients with a morning blood pressure surge $<55 \mathrm{mmHg}$. Pierdominico reached a similar conclusion that stroke had a relationship with an exaggerated early morning blood pressure surge independent of the 24-h average blood pressure [18, 19].

Smoking and alcoholism are controllable risk factors for stroke. Both played an important role in our prediction model, and these were valid for more than $90 \%$ of the males in our cohort. A large number of clinical studies in different races and populations have confirmed the strong association between smoking and stroke, while exposure to secondhand smoke should also be noted. Current smokers are at least two-to-four times more likely to have a stroke than those who never smoked or those who quit smoking 10 years ago [20]. Some

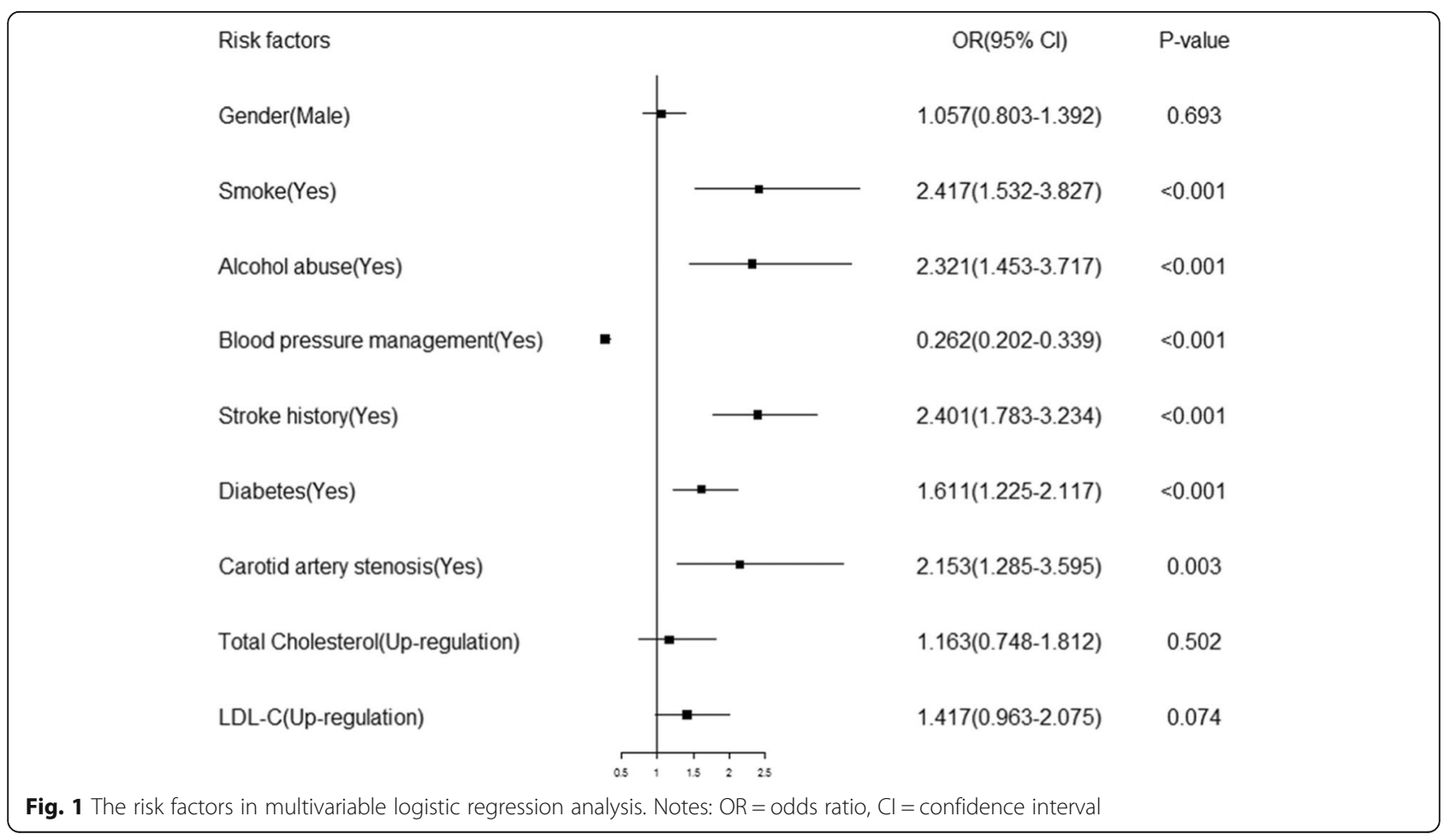




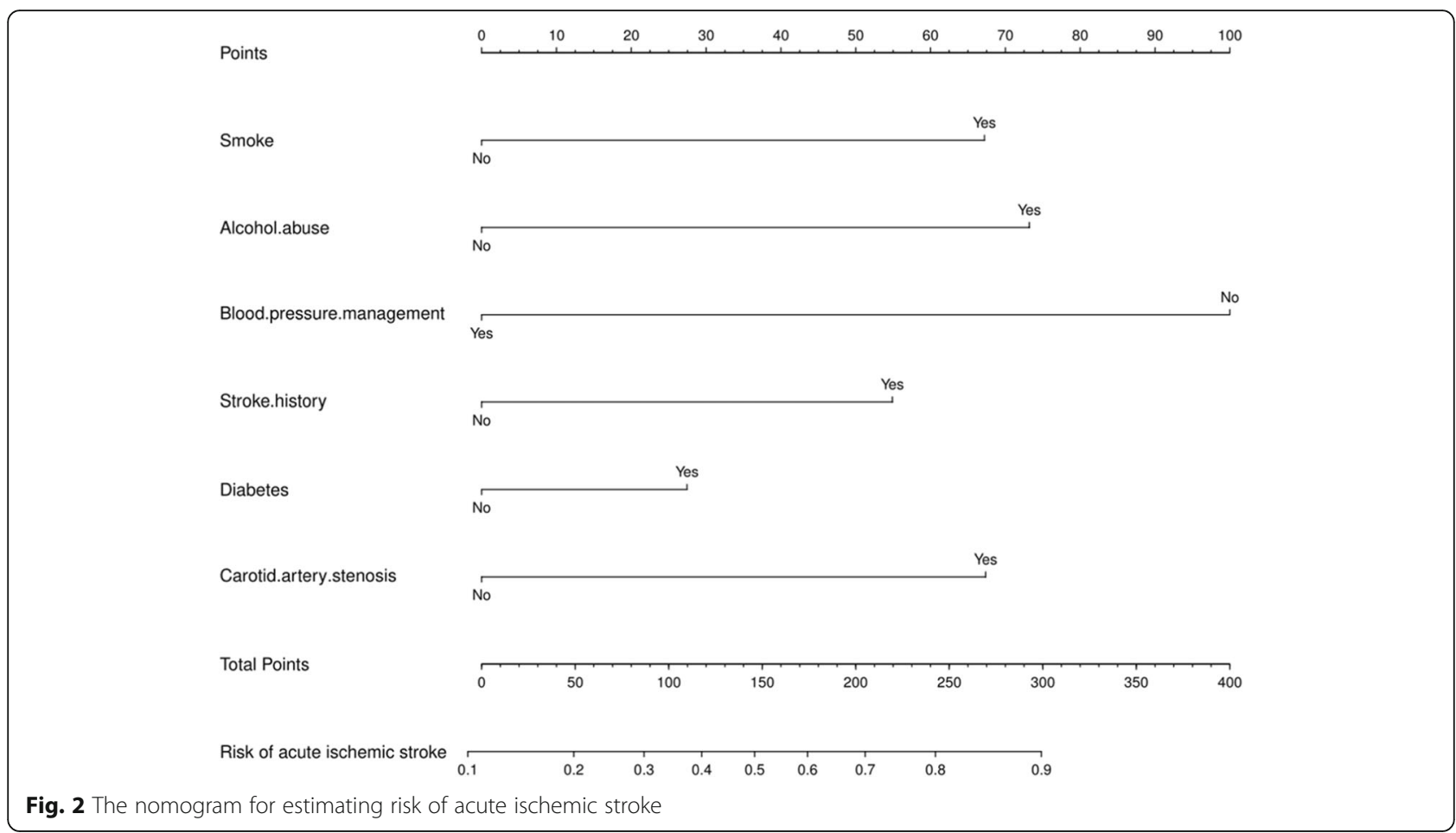

epidemiological studies have demonstrated that the impact of drinking on stroke risk depends on the quantity. A small amount of red wine may reduce the risk of cardiovascular disease and stroke. However, alcohol abuse $(>60 \mathrm{~g} /$ day) is associated with an increased risk of stroke in the long term $[21,22]$.
CAS is a marker of systemic atherosclerosis that can be easily detected by ultrasound. According to studies from the 1980s, the annual risk of ipsilateral stroke was $3 \%$ in patients with a CAS $\geq 50 \%$, which increased to $5.5 \%$ in patients with a CAS $>75 \%$. With the widespread use of preventive drugs, the annual risk of stroke has
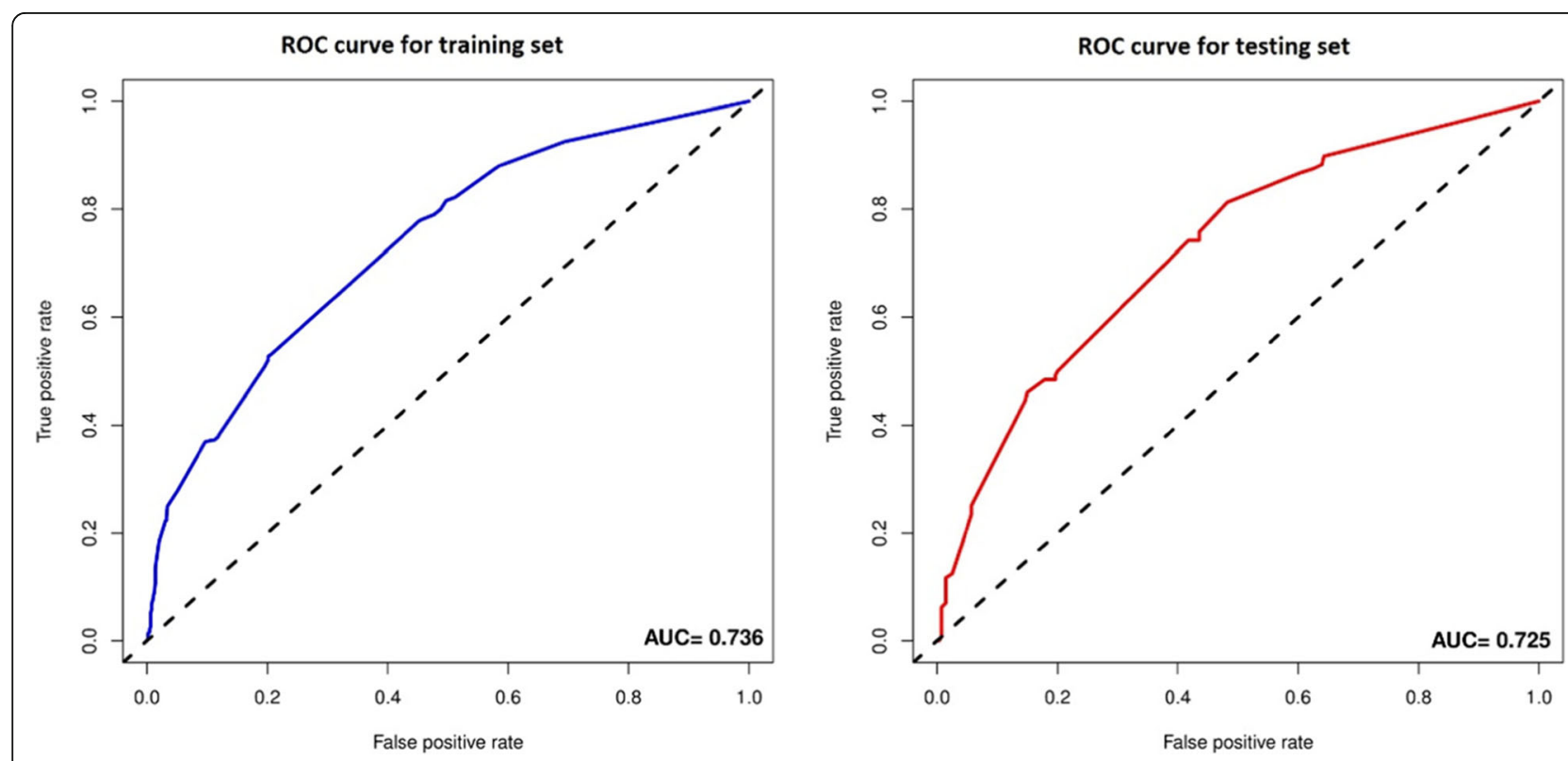

Fig. 3 ROC curve of the nomogram. Notes: The ROC curves of the training set and testing set. The AUC of the training set is 0.736 and 0.725 in the testing set 

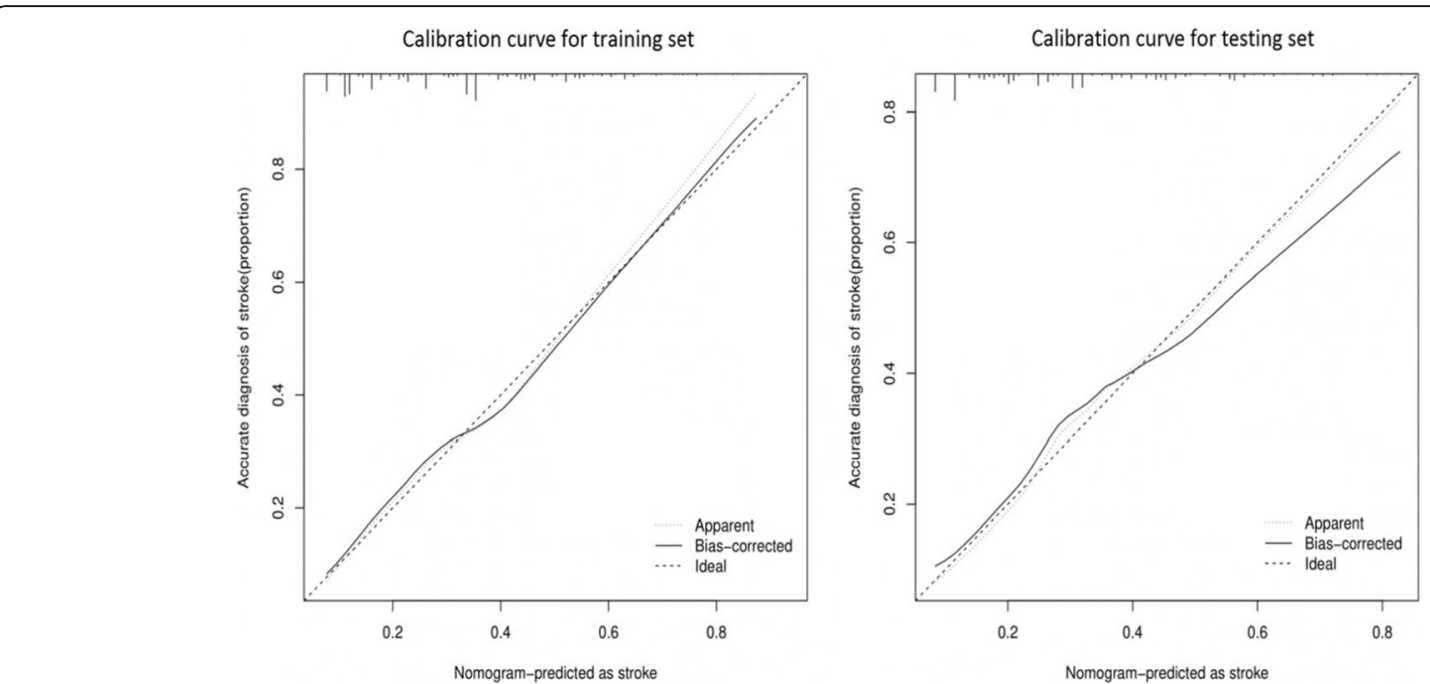

Fig. 4 Calibration curve of the nomogram. Notes: The $x$-axis represents the risk predicted by the nomogram. The $y$-axis represents the patients diagnosed with acute ischemic stroke. The diagonal dotted line represents a perfect prediction by an ideal model. The apparent line represents the performance of the nomogram

been reduced to $0.34 \%$ for patients with a CAS $\geq 50 \%$ in contemporary studies $[23,24]$.

Other risk factors that are not included in our nomogram, such as age, total cholesterol and LDL-cholesterol [25-27], were proven to be related to stroke by an abundance of clinical trials and should be considered by clinicians. It is worth noting that elderly patients usually present with multiple chronic diseases, such as hypertension, diabetes and coronary heart disease. The risk of ischemic stroke caused by pathological changes of organs caused by these diseases may be more serious than that caused by physiological aging [28]. Additionally, elderly patients often do not adhere to prescribed treatments. The direct visual display of the nomogram model can play a role in educating elderly patients and increase their compliance to treatment.

In the era of artificial intelligence, machine learning has become a popular method in data analysis. It utilizes

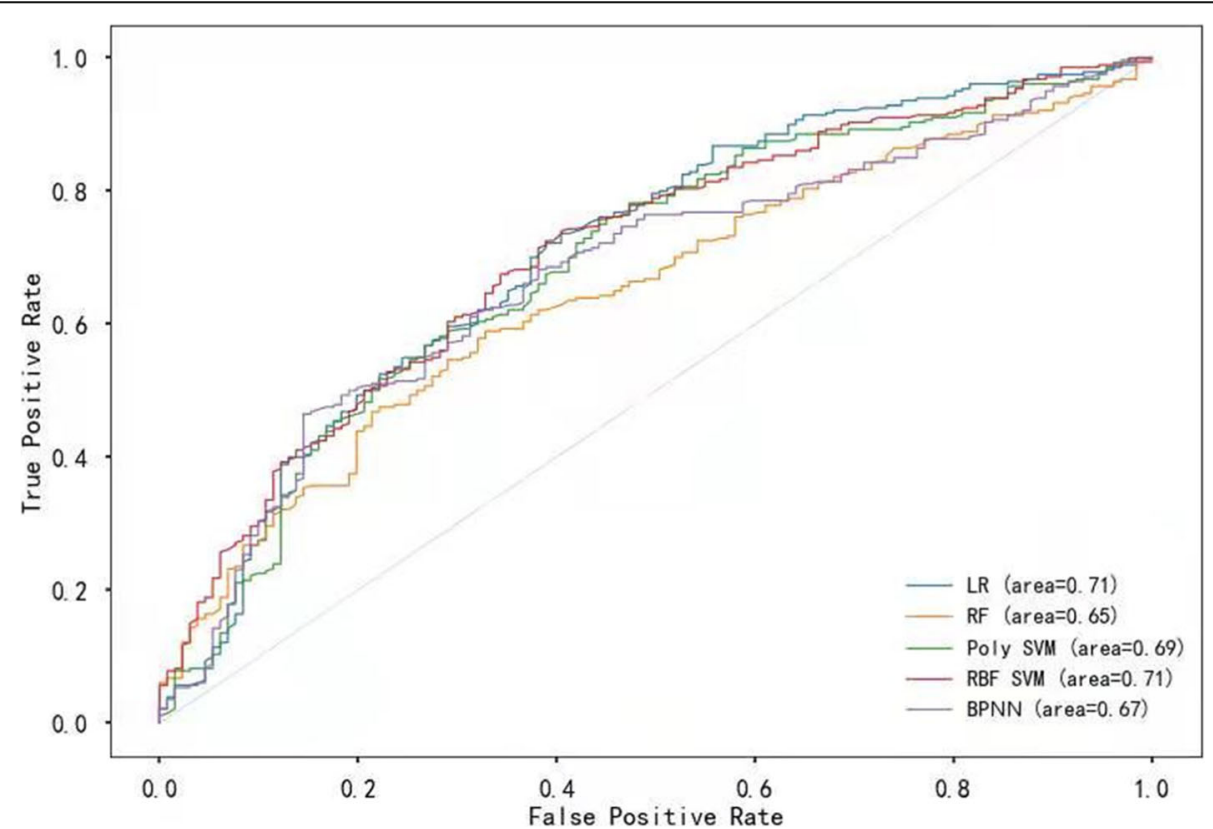

Fig. 5 ROC curve of the machine learning and multivariable logistic regression. Notes: $L R=$ logistic regression, $R F=$ random forest, $P$ oly $S V M=$ support vector machine with polynomial kernel, RBF SVM = support vector machine with radial basis function kernel, BPNN = backpropagation neural network 
mathematical models and training data to make predictions $[29,30]$. The random forest, support vector machines, and backpropagation neural networks are three representative algorithms of machine learning that are increasingly used in the prediction of adverse events in clinical practice or biological research in tumor [31, 32]. Although these machine learning algorithms have attracted much attention with the availability of increasingly voluminous datasets (such as electronic medical records), the internal process of which is similar to a "black box" with poor interpretability and visualization, limit their practical application.

In a number of reports, the results of multivariable logistic regression analysis as the classic reference standard were compared with those of machine learning algorithms. In our study, the machine learning algorithms offered no obvious advantage over multivariable logistic regression in evaluating a binary categorical problem (whether or not patients will suffer an acute ischemic stroke). This conclusion is the same as that of several recent studies [14, 33].

Our prediction model based on multivariable logistic regression analysis not only has considerable accuracy but also can be visualized by a nomogram, which is convenient for its clinical application.

\section{Limitations}

This study was a single-center retrospective study, which limits its generalizability. As a retrospective study, potential selection bias was inevitable. Furthermore, there are numerous other stroke-related risk factors, such as the body mass index, diet habits, and physical exercise, that were not analyzed because they were not reported in the electronic records of patients.

\section{Abbreviations \\ TC: Total cholesterol; LDL-C: Low density lipoprotein cholesterol; HDL-C: High density lipoprotein cholesterol; OR: Odds ratio; Cl: Confidence interval; ROC: Receiver operating characteristic curve; AUC: Area under the curve; RF: Random forest; SVM: Support vector machine; BPNN: Back propagation neural network}

\section{Authors' contributions}

Xifeng Zheng, Fang Fang and Weidong Nong were involved in the conception and design of the study. Xifeng Zheng and Fang Fang were responsible for software, visualization and article writing. Weidong Nong and Yu Yang were involved in analysis of the data. Xifeng Zheng and Dehui Feng provided scientific supervision. All authors reviewed and approved the final manuscript.

\section{Funding}

The research belongs to one of Zhanjiang science and technology programs, No. 2021 B01364

\section{Availability of data and materials}

The datasets used and/or analyzed during the current study are available from the corresponding author on reasonable request.

\section{Declarations}

Ethics approval and consent to participate

The research was approved by the Ethics Committee of the Affiliated Hospital of Guangdong Medical University and the informed consent was waived due to the retrospective nature of the analysis. Researchers tried their best to protect the information from disclosure.

\section{Consent for publication}

Not Applicable.

\section{Competing interests}

The authors declared that they have no conflicts of interests to this work. We declare that we do not have any commercial or associative interests that represents a conflict of interests in connection with the work submitted.

\section{Author details}

${ }^{1}$ Department of Geriatrics, Affiliated Hospital of Guangdong Medical University, No.57, South of Renming Road, Zhanjiang, Guangdong 524001, People's Republic of China. ${ }^{2}$ Department of General Medicine, Huazhong University of Science and Technology Union Shenzhen Hospital, Shenzhen, Guangdong, China. ${ }^{3}$ Department of Neurology, Affiliated Minzu Hospital of Guangxi Medical University, Nanning, Guangxi, China.

Received: 27 November 2020 Accepted: 18 July 2021

Published online: 09 August 2021

\section{References}

1. Kuklina EV, Tong X, George MG, Bansil P. Epidemiology and prevention of stroke: a worldwide perspective. Expert Rev Neurother. 2012;12(2):199-208. https://doi.org/10.1586/ern.11.99.

2. Wu S, Wu B, Liu M, Chen Z, Wang W, Anderson CS, et al. Stroke in China: advances and challenges in epidemiology, prevention, and management. Lancet Neurol. 2019;18(4):394-405. https://doi.org/10.1016/S1474-4422(18)3 0500-3.

3. Guo J, Zhu YC, Chen YP, Hu Y, Tang XW, Zhang B. The dynamics of hypertension prevalence, awareness, treatment, control and associated factors in chinese adults: results from chns 1991-2011. J Hypertens. 2015; 33(8):1688-96. https://doi.org/10.1097/HJH.0000000000000594.

4. Balachandran VP, Gonen M, Smith JJ, DeMatteo RP. Nomograms in oncology: more than meets the eye. Lancet Oncol. 2015;16(4):e173-80. https://doi.org/10.1016/S1470-2045(14)71116-7.

5. Zheng X, Huang R, Liu G, Jia Z, Chen K, He Y. Development and verification of a predictive nomogram to evaluate the risk of complicating ventricular tachyarrhythmia after acute myocardial infarction during hospitalization: a retrospective analysis. Am J Emerg Med. 2020. https://doi.org/10.1016/j.a jem.2020.10.052

6. World Health Organization. Decade of healthy ageing: Baseline report: Summary. 2021

7. Wang J, Wen X, Li W, Li X, Wang Y, Lu W. Risk factors for stroke in the chinese population: a systematic review and meta-analysis. J Stroke Cerebrovasc Dis. 2017;26(3):509-17. https://doi.org/10.1016/j. jstrokecerebrovasdis.2016.12.002.

8. Powers WJ, Rabinstein AA, Ackerson T, Adeoye OM, Bambakidis NC, Becker $K$, et al. 2018 guidelines for the early management of patients with acute ischemic stroke: a guideline for healthcare professionals from the american heart association/american stroke association. Stroke. 2018;49(3):e46-e110. https://doi.org/10.1161/STR.0000000000000158.

9. Virani SS, Alonso A, Aparicio HJ, Benjamin EJ, Tsao CW. Heart disease and stroke statistics - 2021 update: a report from the american heart association. Circulation. 2021;143(8):e254-743. https://doi.org/10.1161/CIR. 0000000000000950.

10. Williams B, Mancia G, Spiering W, Agabiti Rosei E, Azizi M, Burnier M, et al. 2018 esc/esh guidelines for the management of arterial hypertension: the task force for the management of arterial hypertension of the european society of cardiology (esc) and the european society of hypertension (esh). Eur Heart J. 2018;39(33):3021-104. https://doi.org/10.1093/eurheartj/ehy339.

11. Peduzzi $P$, Concato J, Kemper $E$, Holford TR, Feinstein AR. A simulation study of the number of events per variable in logistic regression analysis. J Clin Epidemiol. 1996:49(12):1373-9. https://doi.org/10.1016/ S0895-4356(96)00236-3. 
12. Huang YQ, Liang CH, He L, Tian J, Liang CS, Chen X, et al. Development and validation of a radiomics nomogram for preoperative prediction of lymph node metastasis in colorectal cancer. J Clin Oncol. 2016;34(18):2157-64. https://doi.org/10.1200/JCO.2015.65.9128.

13. Kramer AA, Zimmerman JE. Assessing the calibration of mortality benchmarks in critical care: the Hosmer-lemeshow test revisited. Crit Care Med. 2007;35(9):2052-6. https://doi.org/10.1097/01.CCM.0000275267.64078 BO.

14. Gravesteijn BY, Nieboer D, Ercole A, Lingsma HF, Zoerle T. Machine learning algorithms performed no better than regression models for prognostication in traumatic brain injury. J Clin Epidemiol. 2020;122:95-107. https://doi.org/1 0.1016/j.jclinepi.2020.03.005.

15. Shantsila A, Lip GYH. Guideline: Acp and aafp recommend systolic bp targets based on history and risk level in adults 60 years of age. Ann Intern Med. 2017;166(8):JC38. https://doi.org/10.7326/ACPJC-2017-166-8-038.

16. Law MR, Morris JK, Wald NJ. Use of blood pressure lowering drugs in the prevention of cardiovascular disease: meta-analysis of 147 randomised trials in the context of expectations from prospective epidemiological studies. BMJ. 2009:338(may19 1):b1665. https://doi.org/10.1136/bmj.b1665.

17. Bulpitt CJ, Beckett NS, Cooke J, Dumitrascu DL, Gil-Extremera B, Nachev C, et al. Results of the pilot study for the hypertension in the very elderly trial. J Hypertens. 2003;21(12):2409-17. https://doi.org/10.1097/00004872-200312 000-00030.

18. Sogunuru GP, Kario K, Shin J, Chen CH, Buranakitjaroen P, Chia YC, et al. Morning surge in blood pressure and blood pressure variability in asia: evidence and statement from the hope asia network. J Clin Hypertens (Greenwich). 2019;21:324-34.

19. Kario K, Pickering TG, Umeda Y, Hoshide S, Hoshide $Y$, Morinari M, et al. Morning surge in blood pressure as a predictor of silent and clinical cerebrovascular disease in elderly hypertensives: a prospective study. Circulation. 2003;107(10):1401-6. https://doi.org/10.1161/01.CIR.0000056521. 67546.AA.

20. Shah RS, Cole JW. Smoking and stroke: the more you smoke the more you stroke. Expert Rev Cardiovasc Ther. 2010;8(7):917-32. https://doi.org/10.1586/ erc.10.56.

21. Klatsky AL. Alcohol and cardiovascular health. Physiol Behav. 2010;100(1):7681. https://doi.org/10.1016/j.physbeh.2009.12.019.

22. Ronksley PE, Brien SE, Turner BJ, Mukamal KJ, Ghali WA. Association of alcohol consumption with selected cardiovascular disease outcomes: a systematic review and meta-analysis. BMJ. 2011;342(feb22 1):d671. https:// doi.org/10.1136/bmj.d671.

23. Aday AW, Beckman JA. Medical management of asymptomatic carotid artery stenosis. Prog Cardiovasc Dis. 2017;59(6):585-90. https://doi.org/10.1 016/j.pcad.2017.05.008

24. Marquardt L, Geraghty OC, Mehta Z, Rothwell PM. Low risk of ipsilateral stroke in patients with asymptomatic carotid stenosis on best medical treatment: a prospective, population-based study. Stroke. 2010;41(1):e11-7. https://doi.org/10.1161/STROKEAHA.109.561837.

25. Cholesterol Treatment Trialists C, Baigent C, Blackwell L, Emberson J, Holland LE, Reith C, et al. Efficacy and safety of more intensive lowering of Idl cholesterol: A meta-analysis of data from 170,000 participants in 26 randomised trials. Lancet. 2010;376:1670-81.

26. Hackam DG, Hegele RA. Cholesterol lowering and prevention of stroke. Stroke. 2019;50(2):537-41. https://doi.org/10.1161/STROKEAHA.118.023167.

27. De Caterina R, Scarano M, Marfisi R, Lucisano G, Palma F, Tatasciore A, et al. Cholesterol-lowering interventions and stroke: insights from a meta-analysis of randomized controlled trials. J Am Coll Cardiol. 2010;55(3):198-211. https://doi.org/10.1016/j.jacc.2009.07.062.

28. Spannella F, Di Pentima C, Giulietti F, Buscarini S, Ristori L, Giordano P, et al. Prevalence of subclinical carotid atherosclerosis and role of cardiovascular risk factors in older adults: atherosclerosis and aging are not synonyms. High Blood Pressure Cardiovasc Prev. 2020;27(3):231-8.

29. Shameer $K$, et al. Machine learning in cardiovascular medicine: are we there yet? Heart. 2018;104(14):1156-64.

30. Leiner T, Rueckert D, Suinesiaputra A, Baeler B, Young AA. Machine learning in cardiovascular magnetic resonance: basic concepts and applications. J Cardiovasc Magn Reson. 2019;21(1):61. https://doi.org/10.1186/s12968-0190575-y.

31. Han L, Yuan Y, Zheng S, Yang Y, Li J, Edgerton ME, et al. The pan-cancer analysis of pseudogene expression reveals biologically and clinically relevant tumour subtypes. Nat Commun. 2014;5(1):3963. https://doi.org/10.1038/ ncomms4963.

32. Chicco D, Jurman G. Machine learning can predict survival of patients with heart failure from serum creatinine and ejection fraction alone. BMC Med Inform Dec Making. 2020;20(1):16. https://doi.org/10.1186/s12911-020-1023-5.

33. Christodoulou E, Ma J, Collins GS, Steyerberg EW, Verbakel JY, Van Calster B. A systematic review shows no performance benefit of machine learning over logistic regression for clinical prediction models. J Clin Epidemiol. 2019; 110:12-22. https://doi.org/10.1016/j.jclinepi.2019.02.004

\section{Publisher's Note}

Springer Nature remains neutral with regard to jurisdictional claims in published maps and institutional affiliations.

\section{Ready to submit your research? Choose BMC and benefit from:}

- fast, convenient online submission

- thorough peer review by experienced researchers in your field

- rapid publication on acceptance

- support for research data, including large and complex data types

- gold Open Access which fosters wider collaboration and increased citations

- maximum visibility for your research: over $100 \mathrm{M}$ website views per year

At BMC, research is always in progress.

Learn more biomedcentral.com/submissions 